\title{
Effect of Wall-Assisted Exercises on the Balance and Walking Ability of Visually Impaired Individuals
}

\author{
Ceren Suveren-Erdogan ${ }^{1}$ \\ ${ }^{1}$ Faculty of Sport Science, Gazi University, Ankara, Turkey \\ Correspondence: Ceren Suveren-Erdoğan, Faculty of Sport Science, Gazi University, Ankara, Turkey, Abant \\ Street No:12 Gazimahallesi, Yenimahalle, Ankara, Turkey.
}

Received: September 15, 2018

Accepted: October 11, 2018 Online Published: October 23, 2018

doi:10.5539/jel.v7n6p191

URL: https://doi.org/10.5539/jel.v7n6p191

\begin{abstract}
This study aims to ensure that wall-assisted exercises are among the primary exercises for visually impaired individuals, to observe the effect of these exercises on balance and walking abilities, be able to make efficient progress in a short period of time, to support these individuals' self-confidence and ability to act independently and to reduce the risks that may arise from loss of balance.7 sedentary individuals with B2 and B3 levels visual impairment between the ages of 16 and 18 voluntarily participated in the study. Once verbal information was given about the study to be conducted to the visually impaired participants, they were asked to take 15 brisk steps and 15 heel-toe steps to determine their spatial orientation disorders and balance losses. During the following 10 weeks, the study involving 5 movements to be applied by means of a wall were applied in company with the verbal and physical corrections of an instructor for 40 minutes a day and 1 day a week. Tests were repeated after 10 weeks. Due to the low number of subjects, the participants were not separated in terms of their gender and the data of the study were expressed in graphics.Looking at the pre-test and post-test averages, the 15 -step heel-toe walking duration was 14.71 seconds and the balance loss values decreased by 4.86 points while 15 -step brisk walking duration was 2.71 and directional loss decreased by 1.72 points. The study revealed that balance loss and spatial orientation disorder of visually impaired individuals who applied wall-assisted exercises in company with verbal notification and physical aid decreased compared to the pre-study period. These results point to the fact that wall-assisted exercises are quite useful and applicable in the walking training of visually impaired individuals.
\end{abstract}

Keywords: visually impaired, wall-assisted exercises, balance

\section{Introduction}

Sport training is of grave importance for visually impaired individuals (Suveren-Erdoğan \& Suveren, 2018). In visually impaired individuals, the ability to act independently begins to develop with delay (Sarimski, 1990) and balance loss along with different postures and walking styles such as extending hands forward, walking with slow steps to avoid accidents and to move safely can be observed in these individuals (Arslantekin, 2014; Tuncer et al., 1999).

Physical activity is extremely necessary to compensate for the developmental retardation, to eliminate the problem of independent movement in social life by reducing the obstacle perception problems, to develop self-confidence and to ensure regular muscular activation and the necessary motivation to move (Havik et al., 2010).

Individualized physical programs should be prepared to meet the needs of individuals with impairments. These adapted studies should aim for a corrective, competent, safe, personally satisfying and successful experience (Winnick, 2017). Such studies support the optimal personal development and self-actualization of visually impaired individuals and can facilitate their lives by increasing their living standards (Gallahue, 1987).

The disabled individual needs appropriate spatial and physical awareness as well as skills, socialization and motor skills such as endurance, strength, balance and coordination to act adequately and independently (Kalia et al., 2010; Altunay, 2003; Winnick, 2017). Ensuring that people see a reference point helps to provide and maintain stability. Since vision is an important factor supporting balance, balance skills and physical awareness may develop with delay in visually impaired individuals (Casselbrand et al., 2007). 
Individuals who have lost their vision and are not capable of seeing experience loss of balance due to obstacle perception problems. These balance losses cause injuries especially during walking and therefore social life is negatively affected (Jazi et al., 2012; Ray et al., 2008; Coughlan, 2012; Montarzino et al., 2007). Walking, posture, body control, and body management are all part of the independent movement (Y1lmaz et al., 2013; Pogrund et al., 1998).

This study aims to ensure that wall-assisted exercises are among the primary exercises for visually impaired individuals, to observe the effect of these exercises on balance and walking abilities, be able to make efficient progress in a short period of time, to support these individuals' self-confidence and ability to act independently and to reduce the risks that may arise from loss of balance.

\section{Method}

7 sedentary individuals with B2 and B3 levels visual impairment between the ages of 16 and 18 voluntarily participated in the study. Once verbal information was given about the study to be conducted to the visually impaired participants, they were asked to take 15 brisk steps and 15 heel-toe steps in company with a verbal warning on a straight line to determine their spatial orientation disorders and balance losses. During the following 10 weeks, 5 wall-assisted exercises were applied in company with the verbal and physical corrections of an instructor for 40 minutes a day (10 minutes warm up-30 minutes main activity) and 1 day a week. While the visually impaired participants did wall-assisted exercises, the instructor beat time by either clapping hands or by counting according to the content of the exercise. Tests were repeated after 10 weeks. Due to the low number of subjects, the participants were not separated in terms of their gender and the data of the study were expressed in graphics.

\subsection{Wall-Assisted Exercises}

\subsubsection{Wall-Assisted Squat}

- Stand up straight, leaning against a wall.

- Take a step forward while leaning against the wall, bring the legs together.

- Squat downward with both arms opened parallel to the floor.

- Take support from your legs to go back to the starting position when the angle of the knee is 90 degrees.

\subsubsection{Wall-Assisted Open Leg Forward-Backward Stretch Exercise}

- Basic standing position with one leg open, back leaning against a wall one step in front of the wall

- Lean forward with both arms parallel to the floor and touch the wall behind from between the legs.

- Go back to the starting position. Take the shape of a spring to stretch backwards, raise both arms upward to touch the wall over the head.

- No pause between stretching downwards and upwards.

\subsubsection{Wall-Assisted Stand on a Single Foot}

- Basic standing position in front of the wall with the face facing the wall

- Left arm stretched forward, right hand on the waist, take support from the wall.

- Lift up left leg bent at the knee at a 90 degree.

- Stand on the tip toe of the right leg, wait for 2 seconds, stand on the sole again

- Once the specified number of repetitions is reached, the support arm and feet are changed and the movement continues until the same number of repetitions is reached.

\subsubsection{Wall-Assisted Right-Left Pendulum Movement}

- Before the starting the movement, a balance board with a width of $10 \mathrm{~cm}$ and a length of 3 meters is placed parallel and at an arm's distance to the wall.

- Stand on the balance board with the wall on the right and take support from the wall with the right hand.

- Do pendulum movement is with the left leg.

- Swing the leg as forward and backward as possible in a stretched state during the movement.

- Once the specified number of repetitions is reached, the support arm and feet are changed and the movement continues until the same number of repetitions is reached. 


\subsubsection{Wall-Assisted Right-Left Leg Plane Position}

- Take support from the wall on the right with the right hand.

- Take support from the right leg and take a step backward with the left leg.

- Lean the body downward slowly; lift up the left leg from back and stand in this position for $2 \mathrm{sec}$.

- Once the specified number of repetitions is reached, the support arm and feet are changed and the movement continues until the same number of repetitions is reached.

Table 1. Exercise programme

\begin{tabular}{lll}
\hline First Period (5 weeks) & Reputation & Set \\
Exercise & 10 & 2 \\
\hline Wall-Assisted Squat & 5 & 2 \\
Wall-Assisted Open Leg Forward-Backward Stretch Exercise & $10 \times 2$ (Left-Right) & 2 \\
Wall-Assisted Stand on a Single Foot & $10 \times 2$ (Left-Right) & 2 \\
Wall-Assisted Right-Left Pendulum Movement & $10 \times 2$ (Left-Right) & 2 \\
Wall-Assisted Right-Left Leg Plane Position & & \\
\hline Second Period (5 weeks) & Reputation & Set \\
Exercise & 10 & 3 \\
\hline Wall-Assisted Squat & 5 & 3 \\
Wall-Assisted Open Leg Forward-Backward Stretch Exercise & $10 \times 2$ (Left-Right) & 3 \\
Wall-Assisted Stand on a Single Foot & $10 \times 2$ (Left-Right) & 3 \\
Wall-Assisted Right-Left Pendulum Movement & $10 \times 2$ (Left-Right) & 3 \\
Wall-Assisted Right-Left Leg Plane Position & & \\
\hline
\end{tabular}

\section{Results}

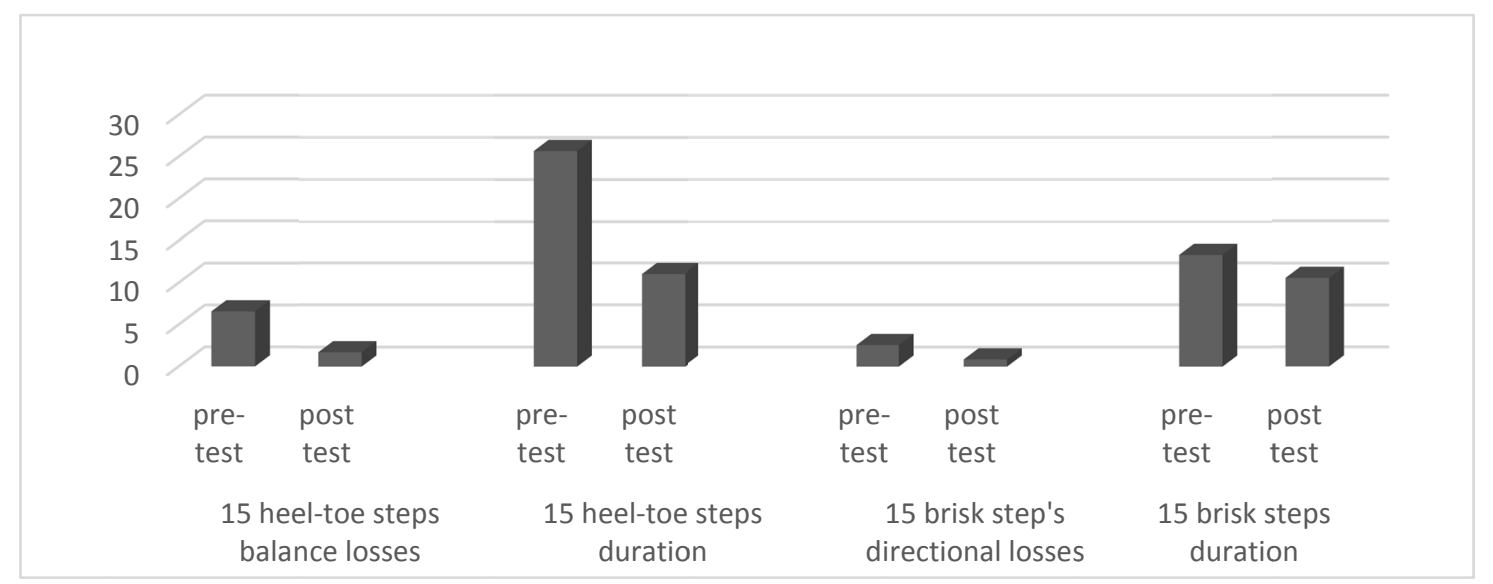

Graphics 1. Loss of balance/direction and walking duration

Looking at the pre-test and post-test averages for the balance loss values 15-steps heel-toe,the balance loss scores decreased to 1.71 from 6.57 . The deffirence between pre test and post test scores is 4.86 point.

Looking at the pre-test and post-test averages for the walking duration 15-steps heel-toe, the duration decreased to 11 seconds from 25.71 seconds. The deffirence between pre test and post test scores is 14.71 seconds.

Looking at the pre-test and post-test averages for the balance loss values 15-steps brisk, the directional loss scores decreased to 0.85 from 2.57. The deffirence between pre test and post test scores is 1.72 point.

Looking at the pre-test and post-test averages for the walking duration 15-steps brisk, the duration decreased to 10.57 seconds from 13.28 seconds.vThe deffirence between pre test and post test scores is 2.71 seconds.

After the study, when the participants were asked about their opinions and achievements about the study, they expressed that they could walk more easily and longer, the anxiety they felt while walking and the width of their movement increased. There was also a visible progress in the movements, posture and self confidence. 


\section{Discussion}

Balance has an important place in the lives of visually impaired individuals. The loss of balance that especially occurs during walking negatively affects the lives of the visually impaired and causes disruptions in social life (Ray et al., 2008; Montarzino et al., 2007; Coughlan et al, 2012). The fact that exercises reduce the adverse effects of falls and injuries due to balance losses is supported by the literature (Jazi et al., 2012; Ray et al., 2008; Lee, 2003). Considering that motor development in visually impaired individuals may become closer to those who can see depending on the nature and content of the training to be provided (Pogrund \& Fazzi, 2002). This study gains more importance and it is thought that it will be more beneficial for the visually impaired individuals if the applications are diversified.

Suveren-Erdoğan and Suveren (2018) emphasized the importance of teaching the basic postures, awareness of the body and spatial orientation in the teaching of movement and sport skills in visually impaired individuals. Pogrund, R. L et al. addressed the importance of wall-assisted applications with a verbal warning in the exercises of visually impaired students.

The fact that the exercises in this study were performed with the help of a wall, with a verbal warning and that they included basic posture techniques makes this study similar to the literature.

Seok-Min, Silliman-French and HyunSu (2010) used the brisk walking technique similar to this study to test dynamic balance performance in their work on Goalball and Track\&Field Athletes.

Suveren-Erdogan, Er and Suveren (2018) investigated the effect of basic standing posture exercises on the walking quality and balance loss of visually impaired individuals and found a decrease in spatial orientation disorders and balance loss. The studies are similar in terms of results, measurement methods and exercise model.

Chen et al. (2011) concluded that taichi exercises had a positive effect on balance development $(\mathrm{P}=0.024)$. Their results are similar to those of this study.

Similar to this study, Cheung et al. (2008) applied a 12-week exercise program to reduce balance loss and falls in the elderly and noted a big improvement $(\mathrm{p}<0.05)$ in the experimental group compared to the control group.

Ak1 et al. (2007) investigated the effect of motor training program on children with low vision. Similar to this study, progress was achieved in all of the applied activities, including the ability to balance.

In his study on visually impaired individuals who do and do not do sports, Kiral (2007) found a statistically significant improvement in the experimental group ( $46.00 \mathrm{sec} \pm 31.69 \mathrm{sec})$ compared to the control group (15.00 $\sec \pm 5.27 \mathrm{sec})(* \mathrm{p}<0.05 *)$ as a result of balance tests.

In their study on sporter and sedentary visually impaired individuals, Akyol et al. (2017) studied the effect of sports on balance and walking distance. The researchers found that the walking distances of national athletes and their balance status were more significant at the level of $p<0.001$ compared to those with sedentary visually impaired individuals and in line with this result. They suggested that visually impaired individuals could be more independent in daily life activities if they include sports in their lives.

Jazi et al. (2012) applied 8-week balance training on visually impaired children to observe dynamic balance development and similarly to this study, the experimental group showed a remarkable improvement in the intra-group and inter-group balance performance $(\mathrm{t}(18)=4.095, \mathrm{p}<0.05)$.

The literature review suggests that exercising has a positive effect on balance development and walking ability of visually impaired individuals. This study also contributes to the literature in this regard.

\section{Conclusion}

As a conclusion of this study, in the visually impaired individuals who performed wall-assisted exercises for 10 weeks, a decrease was observed in walking duration, in spatial orientation disorders and in balance losses during walking. We can conclude that wall-assisted exercises are very beneficial and applicable studies in the walking training of visually impaired individuals.

\section{References}

Ak1, E., Atasavun, S., Turan, A., \& Kayıhan, H. (2007). Training Motor Skills of Children with Low Vision. Perceptual and Motor Skills, 104, 1328-1336.

Akyol, B., Konar, N., \& Taşçı, M. (2017). The Effect Of Sport On Balance And Walking Distance With Visually Impaired People, 12. Niğde University Beden E ğ itimi Ve Spor Bilimleri Magazine, 11(3). 
Altunay, B. (2003) Orientation and independent movement skills in children with vision impairment. In U. Tüfekçioğlu (Ed.), Education of children with hearing, speech and vision problems (pp. 275-300). Eskişehir: Anadolu University Press.

Arslantekin, B. (2014). The Effects of Visual Impairment on Psychomotor Development and Independent Mobility and Supportive Programs. Ergoterapi ve Rehabilitasyon Magazine, 2(3), 165-175.

Casselbrand, M. L., Mandel, E. M., Sparto, P. J., Redfern, M. S., \& Furman, J. M. (2007). Contribution of vision to balance in children four to eight years of age. Ann Otol Rhinol Laryngol, 116(9), 653-657.

Chen, E. W., Fu, A. S., Chan, K. M., \& Tsang, W. W. (2011). The effects of Tai Chi on the balance control of elderly persons with visual impairment: a randomised clinical trial. Age and ageing, 41(2), 254-259. https://doi.org/10.1093/ageing/afr146

Cheung, K. K., Au, K. Y., Lam, W. W., \& Jones, A. Y. (2008). Effects of a structured exercise programme on functional balance in visually impaired elderly living in a residential setting. Hong Kong Physiotherapy Journal, 26(1), 45-50. https://doi.org/10.1016/S1013-7025(09)70007-7

Coughlan, G. F., Fullam, K., Delahunt, E., Gissane, C., \& Caulfield, B. M. (2012). A comparison between performance on selected directions of the star excursion balance test and the Y balance test. Journal of Athletic Training, 47(4), 366-371. https://doi.org/10.4085/1062-6050-47.4.03

Gallahue, D. L. (1987). Developmental Physical Education for Today's Elementary School Children: Instructor's Resource Manual with Transparency Masters. Macmillan.

Havik, E. M., Steyvers, F. J. J. M., Van der Velde, H., Pinkster, J. C., \& Kooijman, A. C. (2010). Design and evaluation of a protocol to assess electronic travel aids for persons who are visually impaired. Journal of Visual Impairment \& Blindness, 84-94.

Jazi, S. D., Purrajabi, F., Movahedi, A., \& Jalali, S. (2012). Effect of selected balance exercises on the dynamic balance of children with visual impairments. Journal of Visual Impairment \& Blindness, 106(8), 466-474.

Kalia, A. A., Legge, G. E., Roy, R., \& Ogale, A. (2010). Assessment of indoor route finding technology for people who are visually impaired. Journal of Visual Impairment \& Blindness, 104(3), 135-147.

Kıral, H. (2007). 13-15 Comparison of Equilibrium Functions of Yas Group Obese and Non-Sports Boys with Disabilities, K.K.T.C. Near East University Institute of Educational Sciences, Department of Physical Education and Sport. Master Thesis, Lefkosa.

Lee, H. K., \& Scudds, R. J. (2003). Comparison of balance in older people with and without visual impairment. Age and ageing, 32(6), 643-649. https://doi.org/10.1093/ageing/afg110

Montarzino, A., Robertson, B., Aspinall, P., Ambrecht, A., Findlay, C., Hine, J., \& Dhillon, B. (2007). The impact of mobility and public transport on the independence of visually impaired people. Visual Impairment Research, 9, 67-82. https://doi.org/10.1080/13882350701673266

Pogrund, R. L., \& Fazzi, D. L. (2002). Early Focus: Workin with young children who are blind and visually impaired and their families (2nd ed.). New York: AFB Press.

Pogrund, R. L., Healy, G., Jones, K., Levack, N., Martin- Curry, S., Martinez, C., Marz, J., Roberson-Smith, B., Vrba, A. (1998). TAPS: Teaching age-appropriate purposeful skills: An orientation and mobility curriculum for students with visual impairments (2nd ed.). Austin: Texas School for the Blind and Visually Impaired.

Ray, C. T., Horvat, M., Croce, R., Mason, R. C., \& Wolf, S. L. (2008). The impact of vision loss on postural sability and balance strategies in individuals with profound vision loss. Gait \& posture, 28(1), 58-61. https://doi.org/10.1016/j.gaitpost.2007.09.010

Sarimski, K. (1990). Angewandte Entwicklungspsychologie in der Fruehfoerderung blinder Kinder. Vierteljahresschrift für Heilpädagogik und ihre Nachbargebiete, 59(3), 354-362.

Seok-Min, Y., Silliman-French, L., \& HyunSu, L. (2010). Comparison of static and dynamic balance of youth goalball and track and field athletes with visual impairments: Case study. Journal of Sport and Leisure Studies, 40, 455-462.

Suveren-Erdoğan, C., \& Suveren, S. (2018). Teaching of Basic Posture Skills in Visually Impaired Individuals and Its Implementation Under Aggravated Conditions. Journal of Education and Learning, 7(3), 109-116. https://doi.org/10.5539/jel.v7n3p109 
Suveren-Erdoğan, C., Er, F., Suveren, S. (2018). The Effect of Basic Position Training on Walking Abilities of Visually Impaired Individuals. Journal of Education and Learning, 7(5). https://doi.org/10.5539/jel.v7n5p130

Tuncer, T., \& Altunay, B. (1999). Orientation to visually impaired students and course analysis in the teaching of independent mobility skills 9. National Special Education Congress. Eskişehir.

Winnick, J. P. (2017). Adaptive Physical Education and Sports (5th ed.). İstanbul: Ekin Books, Sports and Tourism Publication.

Yılmaz, S., Tatar, Y., Ateș, O., \& Tiryaki, E. (2013). Investigation The Effects Of Judo Sport On Blind Students. Sport Science Journal, 3.

\section{Copyrights}

Copyright for this article is retained by the author, with first publication rights granted to the journal.

This is an open-access article distributed under the terms and conditions of the Creative Commons Attribution license (http://creativecommons.org/licenses/by/4.0/). 